\title{
Functionality Based Fixing of Weight for Non-functional parameters of a web service
}

\author{
M.MohemmedSha \\ M.S University \\ Tirunelveli, India
}

\author{
C.Rajalakshmi, I.SherifBaig \\ Department of Computer Science \\ Achariya School of Business and \\ Technology \\ Pondicherry, India
}

\author{
K.Vivekanandan \\ Dept of Computer Science and \\ Engineering \\ Pondicherry Engineering College
}

\begin{abstract}
In recent years, web services open the way to global business development through B2B integration and they used with different business applications to accommodate their services. So while selecting a service, the first preference is given to the functional properties of the web service and then a best web service is selected from the list by considering the expected quality. The QoS of a web service is also depends on the variant nonfunctional parameters of its service which may subject to changes because of network and other related factors. While considering the performance of a service, the overall quality is always preferred but the actual functionality of the service is based on the weight fixed for the non functional parameters like response time, throughput, etc... So assigning functionality based weight for the non functional parameters are used to achieve the assured quality of the service. In this paper we are proposing the system that gives importance for the non functional parameters such as response time, throughput, availability, success ability, reliability for which the weight is set based on functionality and requirement of aparticular business application.
\end{abstract}

Keywords:SOA, SLA, WSLA, WSDL, UDDI, B2B, Quality of Services, QoS, Web Service

\section{INTRODUCTION}

The emergence of Web services make it possible to realize Business-to-Business Interoperability (B2B) by interconnecting Web services provided by various organizations.The presence of multiple Web services with identical functionality, leads to select the best Web service based on their QoS. QoS encompasses a number of nonfunctional properties such as response time, throughput, availability, reliability, and reputation, etc.But setting appropriate weight for the parameters based on the user requirement paves the way to reach the actual functionality of the web service [2]. The static, dynamic attributes that are under and beyond the influence of service providers are also considered to set the weight for the non functional parameters. There are many cases that the web service cannot reach the customers requirement because the appropriate weight is not given to the non-functional parameters while selecting the web service. In this paper calculation of QoS of web service based on its functionality weight is proposed for the successful composition of multiple businesspartners according to some business process

The framework of the proposed functionality based weight fixing for non functional parameter is discussed in section 2 . Section 3 calculates the QoS of the web service for same weights of all parameters and the asserted values of weight as in the WSLA and Section 4 shows the experimental results.

\section{FRAMEWORK FOR}

\section{FUNCTIONALITY BASED WEIGHT}

The framework consistsof the basic web service model components web service provider, web service consumer and the Web Service Level Agreement (WSLA) mutually agreed by both signing parties. In addition it has a third party broker which calculate the QoS information for every customer request into a QoS database by getting the measured values from the customer, provider application and the asserted values in the WSLA.
A measurement service implements the measurement function required both the customer and the service provider. The measurement functionality receives the measured metrics from the system's instrumentation. Instructions on how to measure a particular system parameter are defined in the measurement directives of a WSLA[8].

After getting the parametric values the third party broker receives the weight for each parameter as input from the WSLA that is mutually agreed by the signing parties while selection of the web service. The QoS can be evaluated based on this weight and compared with the assured quality [6]. If there is a violation the same can be reported to the top management of both the signing parties to take immediate action.

\section{EVALUATION OF QOS BASED ON NON FUNCTIONAL PARAMETER WEIGHTS}

Let $\mathrm{WS}_{1}, \mathrm{WS}_{2}, \mathrm{WS}_{3}, \mathrm{WS}_{4}, \mathrm{WS}_{5}$ are the selected web services with the guaranteed level of quality parameters $\left\{\mathrm{P}_{1}, \mathrm{P}_{2}, \mathrm{P}_{3}\right.$ ..Pm $\}$ Where $m(1 \leq \mathrm{i} \leq \mathrm{m})$ in the WSLA.

Here the goal is to satisfy the customer requirements by assigning proper weights to all the non-functional parameters that are considered during the selection of a web service. For that a comparison between QoS for equal weight based parameter and weight based on functionality is made and the importance of fixing weight based on requirement is explained [3]. 


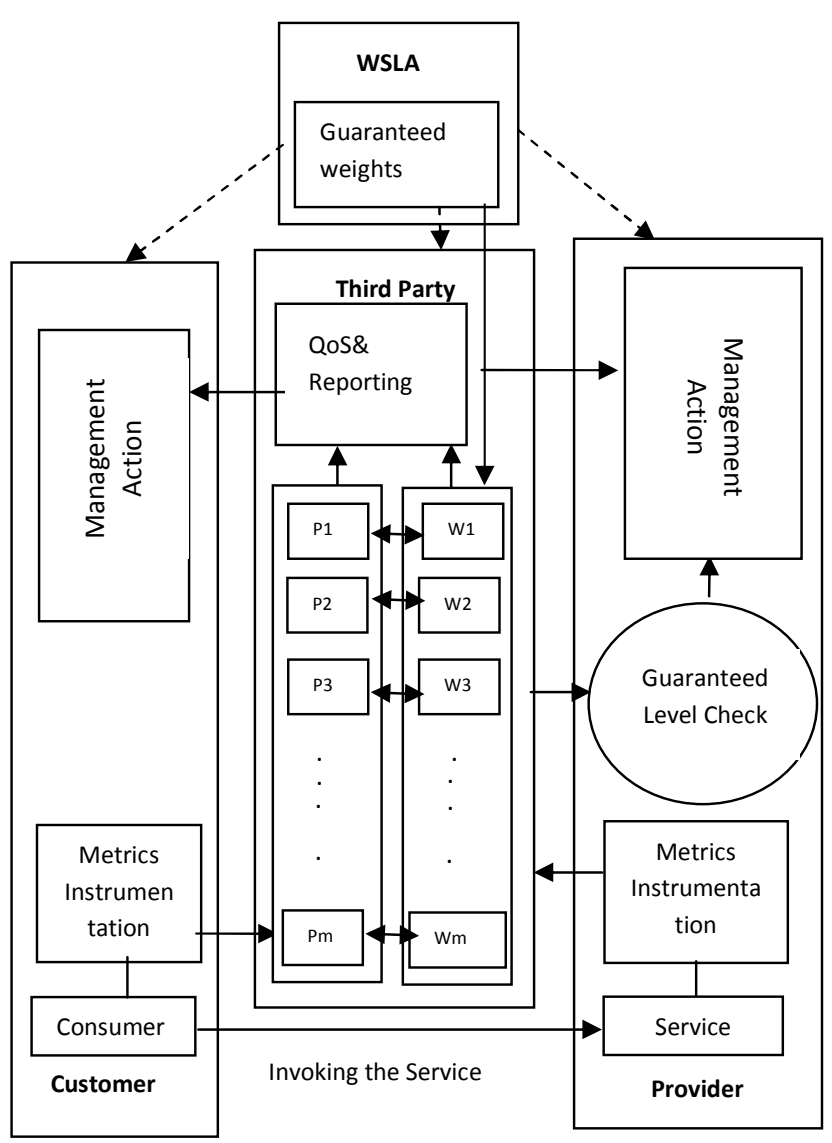

Figure 1. Framework of functionality based weight fixing

The basic metrics are measured by the customer and provider applications when the request is made. A measurement service used by the third party broker get the metrics from both the signatory parties and aggregated into composite metrics and SLA parameters which are used to calculate the actual quality of the web service [1].

Let the broker reports the management about the violation of QoS for every $\mathrm{N}$ requests.

These requests are equally divided into $\mathrm{n}$ sub requests and its average values is recorded and stored in the QoS database. The set $P_{\mathrm{ws} A V G}=\left\{\mathrm{P}_{1 \mathrm{AVG}}, \mathrm{P}_{2 \mathrm{AVG}} \ldots \ldots \mathrm{P}_{\mathrm{m} \mathrm{AVG}}\right\}$ is the average value for each quality parameter of the web service [1].

The parametric values are normalized as $\mathrm{P}_{\mathrm{ws} \mathrm{NOR}}=\left\{\mathrm{P}_{1 \mathrm{NOR}}, \mathrm{P}_{2}\right.$ $\left.{ }_{N O R}, \ldots \ldots . P_{m ~ N O R}\right\}$ and will be presented in the range of $[0,1]$.

The QoS for the web service can be calculated as follows

$$
\text { QoS }=\frac{1}{m} \sum_{j=1}^{m} w_{j} \cdot P_{j N O R}
$$

Where $\mathrm{w}_{1}, \mathrm{w}_{2}, \mathrm{w}_{3}, \ldots \ldots \ldots \mathrm{w}_{\mathrm{m}} \quad$ are the weights assigned for the quality parameters.

The QoS of the web services are calculated in two phase for comparison. In the first phase an equal weight assigned for all parameters and in the second functionality based priority is given to the parameters [9]. The advantage of functionality based weight setting is studied to achieve better quality performance.

\section{EXPERIMENTAL RESULTS}

The average parametric values for the web services for every request 1000 is recorded for five web services under the study is as follows

Table 1. Average Non Functional Parametric Values

\begin{tabular}{|c|c|c|c|c|c|}
\hline & P1 & P2 & P3 & P4 & P5 \\
\hline WS1 & 302.75 & 7.1 & 89 & 90 & 73 \\
\hline WS2 & 482 & 16 & 85 & 95 & 73 \\
\hline WS3 & 3321.4 & 1.4 & 89 & 96 & 73 \\
\hline WS4 & 126.17 & 12 & 98 & 100 & 67 \\
\hline WS5 & 107 & 1.9 & 87 & 95 & 73 \\
\hline
\end{tabular}

The quality values are normalized between $[0,1]$ as follows Table 2. Normalized Parametric Values

\begin{tabular}{|l|l|l|l|l|l|}
\hline & $\mathbf{P 1}_{\text {NOR }}$ & $\mathbf{P 2}_{\text {NOR }}$ & $\mathbf{P 3}_{\text {NOR }}$ & $\mathbf{P 4}_{\text {NOR }}$ & P5 $_{\text {NOR }}$ \\
\hline WS1 & 0.51 & 0.51 & 0.48 & 0.56 & 0.59 \\
\hline WS2 & 0.49 & 0.56 & 0.53 & 0.44 & 0.56 \\
\hline WS3 & 0.39 & 0.37 & 0.45 & 0.45 & 0.41 \\
\hline WS4 & 0.41 & 0.60 & 0.53 & 0.61 & 0.49 \\
\hline WS5 & 0.52 & 0.40 & 0.53 & 0.63 & 0.39 \\
\hline
\end{tabular}

4.1 QoS Based on Equal Weight Parameters

The weight $=.75$ is assigned for all the parameters to find the QoS of the web service

Table 3. Quality of equal weight parameters

\begin{tabular}{|l|r|r|r|r|r|}
\hline & \multicolumn{1}{|c|}{$\mathbf{Q}(\mathbf{P 1})$} & \multicolumn{1}{c|}{$\mathbf{Q}(\mathbf{P} 2)$} & \multicolumn{1}{l|}{$\mathbf{Q}(\mathbf{P 3})$} & \multicolumn{1}{|c|}{$\mathbf{Q}(\mathbf{P 4})$} & \multicolumn{1}{c|}{$\mathbf{Q}(\mathbf{P 5})$} \\
\hline WS1 & 0.38 & 0.38 & 0.36 & 0.42 & 0.44 \\
\hline WS2 & 0.37 & 0.42 & 0.40 & 0.33 & 0.42 \\
\hline WS3 & 0.29 & 0.28 & 0.34 & 0.34 & 0.31 \\
\hline WS4 & 0.31 & 0.45 & 0.40 & 0.46 & 0.37 \\
\hline WS5 & 0.39 & 0.30 & 0.40 & 0.47 & 0.29 \\
\hline
\end{tabular}

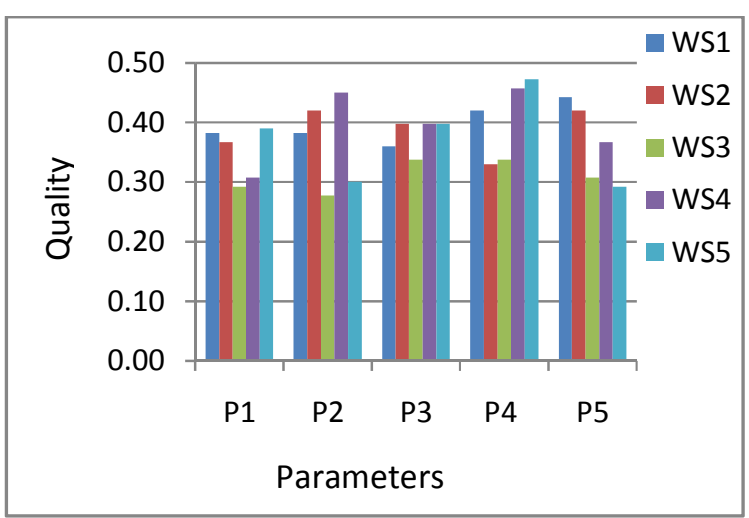

Figure 2. Performance of equal weight parameters 


\subsection{QoS Based on Functionality Weight Parameters}

The following weights are assigned to the web services based on its functionality

Table 4. Functionality weights of web services

\begin{tabular}{|c|c|c|c|c|c|}
\hline & W1 & W2 & W3 & W4 & W5 \\
\hline WS1 & 0.7 & 0.8 & 0.85 & 0.99 & 0.9 \\
\hline WS2 & 0.99 & 0.85 & 0.7 & 0.7 & 0.85 \\
\hline WS3 & 0.8 & 0.7 & 0.9 & 0.85 & 0.9 \\
\hline WS4 & 0.80 & 0.9 & 0.8 & 0.8 & 0.7 \\
\hline WS5 & 0.8 & 0.9 & 0.8 & 0.99 & 0.9 \\
\hline
\end{tabular}

Table 5. Quality of functional weight parameters

\begin{tabular}{|c|c|c|c|c|c|}
\hline & P1 & P2 & P3 & P4 & P5 \\
\hline WS1 & 0.36 & 0.41 & 0.41 & 0.55 & 0.53 \\
\hline WS2 & 0.49 & 0.48 & 0.37 & 0.31 & 0.48 \\
\hline WS3 & 0.31 & 0.26 & 0.41 & 0.38 & 0.37 \\
\hline WS4 & 0.33 & 0.54 & 0.42 & 0.49 & 0.34 \\
\hline WS5 & 0.42 & 0.36 & 0.42 & 0.62 & 0.35 \\
\hline
\end{tabular}

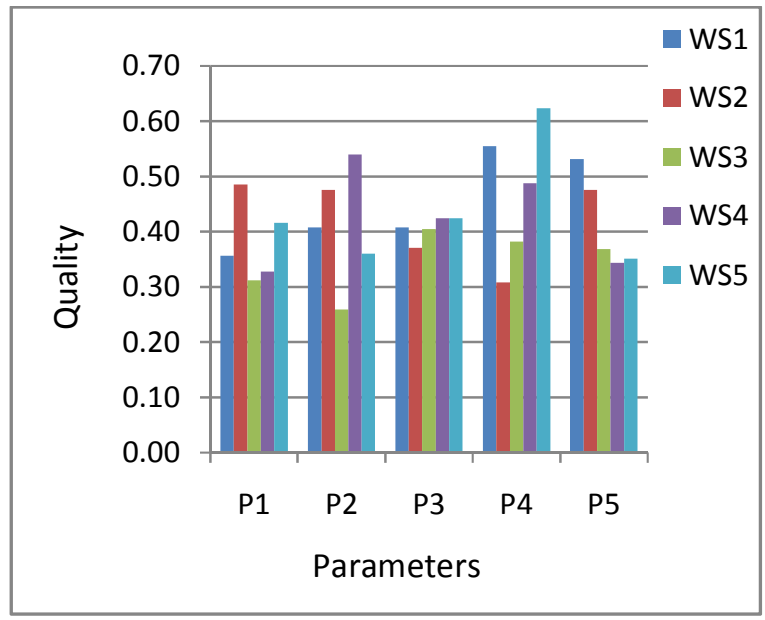

Figure 3. Performance of functional weight parameters

The overall QoS for both the phasesis shown in the table. There is a remarkable improvement in the quality of the web service that implements functionality based weight.

Table 6. QoS of equal and functional weight parameters

\begin{tabular}{|l|r|r|r|r|c|}
\hline QoS of Web Services & WS1 & WS2 & WS3 & WS4 & WS5 \\
\hline Equal Weight & 0.40 & 0.39 & 0.31 & 0.4 & 0.37 \\
\hline Functionality Weight & 0.45 & 0.42 & 0.35 & 0.42 & 0.43 \\
\hline
\end{tabular}

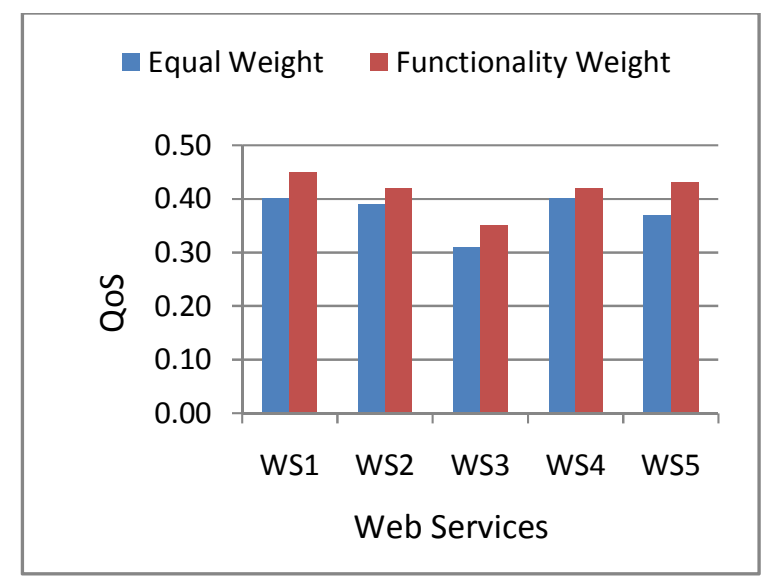

Figure 4. QoS of equal and functionality based Weights

\section{CONCLUSION}

For service selection non-functional QoS parameters are also considered along with the functional requirement. Fixing equal weight to all non functional parameter may result the improvement in overall quality, but considering better weigh for the parameter that improve the functionality of the of the web service. Mentioning the expected quality based on functional weight in the WSLA at the time of selection of a web service will pave the way to reach the expected functional requirement of a web service. Also the assertion in the WSLA is the mutual agreed values between the signing authorities of the web service and it forces the provider to reach the functional requirements for the success of the web service and the entire satisfaction of the customer.

\section{REFERENCES}

[1] M.MohemmedSha, I.SherifBaig, C.Rajalakshmi, P.Balaji and Dr. K.Vivekanandan " Automatic Pricing of Web Services Based on QoS" In: International Journal of Engineering Research and Technology Vol. 1 (02), 2012 ISSN 2278 - 0181.

[2] Al-Masr.E, Mahmoud," Discovering the Best Web Service" In: WWW 2007, Banff, Alberta, Canada, pp. 12572589 (2007).

[3] Ruth Lenon, John Murphy, "You can't always get what you want...-QoS in CWS", Generative Programming \& Component Engineering for QOS Provisioning in Distributor System, UAB Computer \& Information Science.

[4] A.Mani, A. Nagarajan, "Understanding Quality of Service for Web Services", Developer works. 01 Jan 2002. www.ibm.com/developerworks/library/ws-quality.html.

[5] DessislavaPetrova-Antonova, "Cost DependantQoS based Discovery of Web Services”, Demetra EOOD (2010).

[6]MoloodMakhlughian, Seyyed Mohsen Hashemi, YousefRastegari and EmadPejman, "Web Service selection based on Ranking of QoS using Associative Classification" In: International Journal on Web Service Computing (IJWSC), Vol.3, No.1, March 2012.

[7] R. Lennon, J. Murphy, "Web Services Management and Selection": Applied Performance Mechanisms in Proceedings of ICCCN (San Diego, 2005), IEEE, 59. 
[8] Kritikos K, Plexousakis D, "Requirements for QoS-Based Web Service Description and Discovery”, IEEE Transactions on Services Computing, Vol.2, Issue: 4, pp. 320337,December 2009.

[9] P. Pabitha, J. Prabhu, A. Rajesh Kumar, R. Premadhasan, M. Rajaram, "Semantic Annotation and QoS Based Ranking of Web Services using User Preferences" European Journal of Scientific Research ISSN 1450-216X Vol.78 No.2 (2012), pp.293-303@ EuroJournals Publishing, Inc. 2012.

[10] Kopecky J, Vitvar T, Bournez C, and Farrell J, "SAWSDL: Semantic Annotations for WSDL and XML Schema", IEEE Internet Computing Journal, Vol.11, Issue: 6, pp. 60-67, December 2007.

[11] Yousefipour A, Neiat A.G., Mohsenzadeh M, Hemayati M.S., "An Ontology-based Approach for Ranking Suggested
Semantic Web Services ", 6th International Conference on Advanced Information Management and Service(IMS), pp. 17-22, December 2010.

[12] H. Kreger, Web Services Conceptual Architecture 1.0. IBM Software Group, May 2001.

[13] UDDI Version 2.0 API Specification, Universal Description, Discovery and Integration,uddi.org, June 2001.

[14] Dr. E. Kirubakaran, D. Ravindran, Dr. D. I. George Amalarathinam, " Service Discovery Framework with Functional and Non-Functional Information (SDF)" International Journal of Advanced Research in Computer Science and Software Engineering Volume 2, Issue 12, December 2012 ISSN: 2277 128X 